\title{
Textos e contextos do Ensino de História
}

Texts and contexts of History Teaching

Mauro Cezar Coelho*

\section{Molina, Ana Heloisa; Ferreira, Carlos Augusto Lima}

\section{Entre textos e contextos: caminhos do ensino de História}

Curitiba: Ed. CRV, 2016. 556p.

O campo de estudos e pesquisas sobre Ensino de História vive um momento singular. Por vias tortas, encontra-se no bojo das discussões sobre os rumos da disciplina na Educação Básica e no Ensino Superior. As polêmicas em torno da proposição de um currículo comum para a Educação Básica e as propostas de reformulação do Ensino Médio suscitaram uma discussão sobre a História Ensinada, por meio do debate acerca da história que a Escola vai contar.

As vias, então, não são aquelas projetadas pelo campo. As discussões sobre o Ensino de História envolvem muito mais que a definição de conteúdos ou sua tradução para a Educação Básica. Os horizontes do campo vão além das reflexões sobre estratégias didáticas ou o potencial de recursos para o ensino da História e não se confundem técnicas destinadas à operacionalização do saber histórico em situação escolar.

Falamos em estudos e pesquisas porque é isso que os pesquisadores do campo fazem - produzem conhecimento, a partir de pesquisas fundamentadas em critérios da ciência. O esclarecimento é necessário. Situado na interface Educação e História, o campo aborda uma das dimensões da atuação do historiador: o ensino. Ele contradiz uma máxima sempre presente nos bastidores dos cursos de formação de historiadores, segundo a qual Ensino e Pesquisa são incompatíveis, de modo que quem se ocupa de um, necessariamente recusa o outro (o que leva parte significativa das pesquisas envolvendo o campo a não se efetivar nos cursos de pós-graduação em História, mas nos de Educação (Coelho; Coelho, 2015). Um equívoco.

* Doutor em História Social pela Universidade de São Paulo (USP). Professor Adjunto da Universidade Federal do Pará. Belém, PA, Brasil. mauroccoelho@yahoo.com.br 
O campo de pesquisas em Ensino de História é profícuo. Os especialistas, cuja formação foi concluída em programas de pós-graduação em História ou Educação (na imensa maioria dos casos), têm estudado as diversas dimensões que concorrem na História Ensinada. Não por acaso, nos últimos simpósios da Associação Nacional de História, o número de Simpósios Temáticos tem crescido exponencialmente. ${ }^{1}$

Tendo como fontes a legislação educacional, a literatura didática, as concepções de alunos e professores, as políticas educacionais e diversos outros testemunhos, os pesquisadores do campo discutem a História Ensinada, ocupando-se com diferentes questões. Farei referência a três delas. Primeiro, a história que é ensinada: estudos que problematizam os sentidos atribuídos ao saber histórico. ${ }^{2}$ Depois, as formas pelas quais a história ensinada é apreendida, especialmente pelos alunos: estudos sobre os processos de ensino/aprendizagem histórica e sobre os usos dados pelos estudantes à História Ensinada (Cainelli; Schmidt, 1999; Barca; Schmidt, 2009). Por fim, as análises que apontam a especificidade do saber histórico escolar e suas implicações para professores e alunos (Bittencourt, 1997; Fonseca, 1993; 2003; Miranda, 2007; Monteiro, 2007; Cerri, 2011).

Tais pesquisas conjugam conceitos como saber histórico escolar, consciência histórica, cultura escolar, cultura histórica e saber docente, entre outros que, conjugados ao aporte da disciplina, concorrem na análise das fontes e na conformação de modelos interpretativos. Elas, no entanto, guardam compromissos e conexões, e se concretizam na relação com universos distintos daquele do saber historiográfico. Seu comprometimento com os processos educativos e sua vinculação a um interlocutor presente - o qual situa problemas e demanda posicionamentos e ações - demarcam o caráter singular do conhecimento produzido pelo campo: marcadamente, seu caráter aplicado, relacionado à contribuição do saber histórico aos processos de formação de crianças, adolescentes e adultos inseridos na Educação Básica.

O livro Entre textos e contextos - caminhos da história ensinada integra esse conjunto de trabalhos e expressa, muito bem, os rumos do campo nas últimas décadas. Organizado por Ana Heloisa Molina e Carlos Augusto Lima Ferreira, o livro resulta em um panorama amplo, mas acurado, dos caminhos do campo nos últimos anos. Composto por colaboradores de diversas partes do país (alguns deles, contribuintes decisivos na conformação do campo de 
pesquisa, por meio de obras e discussões basilares), o livro abarca reflexões que dão conta de um aspecto estruturante da pesquisa acerca da História Ensinada: o lugar do saber histórico nos processos de aprendizagem na Escola e nos processos de formação dos professores de História. Para tanto, o livro divide-se em seis eixos. Cada um deles aborda aquele aspecto estruturante por meio de um enfoque particular - são eles: "Memórias do Ensino de História": "Currículos e História e Cultura Afro-brasileira e Indígena"; "Livro Didático"; "Formação de Professores"; "Saberes Docentes" e, finalmente, "Ensino e Aprendizagens em História”.

A leitura de cada uma das contribuições deixa claro não apenas o espectro de discussões relacionadas ao Ensino de História, mas também o fato de elas resultarem de uma lida que é própria do historiador e que delimita um campo de pesquisa. O subtítulo não poderia, então, ser mais oportuno, pois as contribuições evidenciam os caminhos do campo e as possibilidades que se abrem para novas investidas, diante da variedade de aportes e perspectivas adotados por pesquisadores com inserções distintas na temática.

O livro participa, ainda, de uma característica comum ao campo - a importância de coletâneas, reunindo contribuições de diversos pesquisadores acerca de um tema. Não é por acaso. Obras assim organizadas permitem o estabelecimento de nexos com uma das dimensões da História Ensinada e sua relação com questões vinculadas às estruturas do saber histórico. Sujeitos, cultura histórica, memória, historiografia, fontes etc. são aspectos recorrentes em tais obras que elegem uma questão e a abordam sob perspectivas, aportes e enfoques temporais distintos. ${ }^{3}$ Isso possibilita o aprofundamento da discussão e oferece uma visão ampliada sobre os temas abordados.

A leitura do livro se impõe por duas razões, pelo menos.

Em primeiro lugar, porque aborda um campo de pesquisa em expansão. Os debates acerca de um currículo nacional e de reformulação do Ensino Médio evidenciam a importância da discussão sobre a História Ensinada. Encará-la como afeita a um campo de pesquisas cujas especificidades o relacionam não apenas à Escola, mas à formação de sujeitos de direitos, como são os cidadãos para quem a Educação se volta, é não somente necessário, mas imperativo. Desse campo vêm surgindo proposições que buscam vincular a disciplina aos processos de formação do homem contemporâneo e, nesse 
sentido, apropria-se das demandas da sociedade brasileira, considerando a sua imensa diversidade.

Em segundo lugar, porque, ao fim e ao cabo, a História e sua conformação como disciplina universitária e escolar nunca se libertou de suas origens - permanece vinculada às pretensões daqueles que veem nela nada mais que uma narrativa sobre as origens da nacionalidade, a qual deve ser incutida nos corações e mentes do povo. Ultrapassar essa visão gestada no século XIX, mas cuja força permanece latente na segunda década do século XXI, deve ser o compromisso e o objetivo de historiadores comprometidos menos com seus gabinetes e mais com a formação da sociedade na qual estão inseridos entre textos $e$ contextos.

\section{REFERÊNCIAS}

BARCA, Isabel; SCHMIDT, Maria Auxiliadora dos S. (Org.) Aprender história: perspectiva da educação histórica. Ijuí: Ed. Unijuí, 2009.

BITTENCOURT, Circe. Ensino de História: fundamentos e métodos. São Paulo: Cortez, 2005. . (Org.) O saber histórico na sala de aula. São Paulo: Contexto, 1997.

CAINELLI, Marlene; SCHMIDT, Maria Auxiliadora dos S. (Org.) Perspectivas do ensino de história. Curitiba: Aos Quatro Ventos, 1999.

CERRI, Luís Fernando. Ensino de História e consciência histórica: implicações didáticas de uma discussão contemporânea. Rio de Janeiro: Ed. FGV, 2011.

. (Org.) O ensino de história e a ditadura militar. Curitiba: Aos Quatro Ventos, 2003.

COELHO, Mauro Cezar; COELHO, Wilma de Nazaré Baía. Lugar de Formação: a produção intelectual discente sobre Ensino de História na Pós-Graduação stricto sensu na Região Norte. História \& Ensino, Londrina, v.21, n.2, p.181-207, jul./dez. 2015.

DIEHL, Astor Antônio (Org.) O livro didático e o currículo de história em transição. Passo Fundo: Ed. UPF, 1999.

FONSECA, Selva Guimarães. Caminhos da história ensinada. São Paulo: Papirus, 1993.

. Didática e prática de ensino de história: experiências, reflexões e aprendizados. Campinas: Papirus, 2003. 
FRANCO, Maria Laura P. B. O livro didático de História do Brasil: a versão fabricada. São Paulo: Global, 1982.

GUIMARÃES, Manoel Luiz Salgado. Historiografia e nação no Brasil: 1838-1857. Rio de Janeiro: Ed. UERJ, 2011.

MIRANDA, Sônia Regina. Sob o signo da memória: cultura escolar, saberes docentes e história ensinada. São Paulo: Ed. Unesp, 2007.

MONTEIRO, Ana Maria. Professores de história: entre saberes e práticas. Rio de Janeiro: Mauad X, 2007.

NOSELLA, Maria de Lourdes C. D. As belas mentiras: a ideologia subjacente aos textos didáticos. São Paulo: Cortez \& Moraes, 1979.

OLIVEIRA, Margarida Dias de; CAINELLI, Marlene Rosa; OLIVEIRA, Almir Félix B. de (Org.) Ensino de História: múltiplos olhares em múltiplos espaços. Natal: Ed. UFRN, 2008.

ROCHA, Helenice; MAGALHÃES, Marcelo; GONTIJO, Rebeca (Org.) A escrita da história escolar: memória e historiografia. Rio de Janeiro: Ed. FGV, 2009.

SILVA, Marcos (org.). História: que ensino é esse? Campinas: Papirus, 2013.

ZAMBONI, Ernesta. Digressões sobre o Ensino de História: memória, história oral e razão histórica. Itajaí: Maria do Cais, 2007.

\section{NOTES}

${ }^{1}$ O levantamento que fizemos considera os simpósios realizados desde 2007. Naquele ano, dos 76 simpósios temáticos, sete voltavam-se para a temática História e Educação. Em 2015, foram 109 grupos de pesquisadores reunidos em simpósios temáticos, dentre eles 13 destinados àquela discussão.

${ }^{2}$ Como exemplos: NOSELLA, 1979; FRANCO, 1982; DIEHL, 1999; BITTENCOURT, 2005; ZAMBONI, 2007; GUIMARÃES, 2011.

${ }^{3}$ Além das obras já citadas, acrescento: CERRI, 2003; OLIVEIRA; CAINELLI; OLIVEIRA, 2008; ROCHA; MAGALHÃES; GONTIJO, 2009; SILVA, 2013.

Resenha recebida em 16 de janeiro de 2017. Aprovada em 20 de fevereiro de 2017. 